\title{
Response probability and response latency to threshold electrocutaneous stimuli*
}

\author{
HARVEY BABKOFF, YEHUDA BERGMAN, and RACHEL BRANDEIS* \\ Bar-Ilan University, Ramat-Gan, Israel
}

\begin{abstract}
A comparison was made between two measures of somatosensory sensitivity, response probability, and reaction time to electrocutaneous constant current pulses of 350-microsec duration. The psychometric functions are steeper than those obtained for other sensory modalities. Similarly, the reaction-time/intensity functions are also steeper than those obtained in other modalities, i.e., larger decreases in reaction time as a function of small increases in stimulus intensity. Ss exposed to a broad stimulus range, including high intensities, yield psychometric and reaction time functions displaced into a higher intensity region than when they are exposed to a narrow low-intensity range of stimuli. The data are discussed in terms of a decision-theory model of reaction time.
\end{abstract}

Recent experiments (Green, 1962; Rollman, $1969 \mathrm{a}, \mathrm{b})$ indicate that the somatosensory system displays great sensitivity to small changes in the intensity of threshold electrocutaneous stimuli. Rollman (1969a) has shown that psychometric functions obtained by using electrocu taneous single-pulse stimuli applied to the skin in the region of the ulnar nerve are very steep compared to visual and auditory data. For example, according to Rollman, the steepness of the psychometric function (measured as the ratio of the standard deviation to the mean threshold current, $\sigma / \mu$ ) generated by electrocutaneous stimulation ranges from 0.04 to 0.31 with a median of 0.08 as compared to the $\sigma / \mu$ ratio for psychometric functions generated for other sensory modalities which are four to eight times as large. Similar differences between the somatosensory system and other sensory modalities have also been reported with regard to the steepness of magnitude estimation functions. Rollman points out, however, that although cutaneous magnitude estimation functions derived by electrical stimulation are quite steep, similar functions derived by other means of cutaneous stimulation, e.g., vibration and pressure, are one-half to one-third as steep. Hahn (1958) had also reported psychophysical data which indicate very short time constants using electrocutaneous stimuli.

There has been some controversy concerning the interpretation of these data (Hahn, 1958; Rollman, 1969a). However, regardless of interpretation, it is, nevertheless, clear that electrocutaneous stimulation of skin in the vicinity of the ulnar or median nerve produces very steep psychophysical functions, indicating

*The authors would like to acknowledge the aid of Jacob Gutgold in building and servicing the equipment, and thank the research committee of Bar-Ilan University for the research funds that made this study possible. We also wish to thank Drs. Bruder and Kietzman, of Biometrics Research, New York State Department of Mental Hygiene, for making their data available. We would like to thank Dr. Kietzman, of Biometrics Research, and Professor Pollack, of the University of Michigan, for their criticism and suggestions. Our thanks also go to Dr. Snyder, of the Bar-Ilan Computer Center, and to Dr. Fleiss, of Biometrics Research. a high degree of sensitivity and steep magnitude growth.

All of the measures from which these conclusions are drawn were psychophysical, utilizing classical (Hahn, 1958; Green, 1962; Rollman, 1969a) as well as more recent signal detection procedures (Rollman, 1969b). The studies reported in this paper were designed to broaden the investigation of electrocutaneous stimulation by utilizing another response class measure, simple reaction time, to test the reported steepness of the sensory function found for this modality.

There has been a recent increase in the use of response latencies to test psychophysical findings. Some studies have emphasized the more theoretical aspects of the use of reaction time (e.g., McGill, 1961, 1963; Vaughan, Costa, \& Gilden, 1966; Luce \& Green, 1972), while others have emphasized the more methodological aspects of response latencies (e.g., Carterette et al, 1965; Emmerich et al, 1972; Gescheider et al, 1973). A further use of simple reaction time has been made to test the generality of laws generated by psychophysical techniques (e.g., Raab, 1962; Raab \& Fehrer, 1962; Grossberg, 1968, 1970; Kietzman \& Gillam, 1972; Bruder \& Kietzman, 1973). These techniques often use both psychophysical and reaction time measures to test the effects of the same stimulus manipulations (Grossberg, 1968; Kietzman \& Gillam, 1972; Bruder \& Kietzman, 1973). This latter use of reaction time emphasizes the notion that more may be learned about the mechanisms involved about sensory processes by discovering the extent to which any given "law" of sensory function is invariant across different response class measures. Certain laws of sensory function obtained via psychophysical methods such as magnitude estimation seem to apply when the reaction time is measured as a function of the same stimulus manipulations (McGill, 1963; Vaughan, Costa, \& Gilden, 1966; Luce \& Green, 1972; Bruder \& Kietzman, 1973). Some recent experiments seem to imply, however, that this is not true for all findings regarding sensory 
functions based upon psychophysical measures. Some studies imply that reaction time measures may not yield the same time constants found for psychophysical measures (Raab, 1962; Kietzman \& Gillam, 1972; Bruder \& Kietzman, 1973) or may not even yield the same findings at all (Grossberg, 1968; Teichner \& Krebs, 1972). It is, therefore, not a priori certain that reaction time to electrocutaneous stimuli should yield steep functions and show the same sensitivity to small changes in intensity which are seen in psychophysical functions. The question may therefore be raised: Can one similarly expect steeper reaction time functions, i.e., reaction time decreasing as a function of small increases in the intensity of electrocutaneous stimuli, relative to the functions describing decreases in reaction time as a function of increases in visual or auditory stimuli?

Similar to other sensory modalities, simple reaction time to electrocutaneous stimuli decreases as a function of increases in stimulus intensity (Sticht \& Foulke, $1966 \mathrm{a}, \mathrm{b})$. In other modalities, reaction time continues to decrease over the entire intensity range to which psychophysical responses may be obtained, although the major decrease in reaction time occurs in the vicinity of threshold. Sticht and Foulke (1969b) measured the reaction time to a $70-\mathrm{Hz}$ electrocutaneous stimulus for intensities ranging from 2 to $10 \mathrm{~dB}$ above "offset" threshold (defined as the intensity corresponding to $50 \%$ detection of the offset of the signal). These levels are generally sufficiently high to obtain responses to the onset of the stimuli on $100 \%$ of the trials. No data are presently available on the reaction time to electrocutaneous pulses ranging in intensity from below $100 \%$ detection to suprathreshold levels. Furthermore, no data have been reported on the frequency of response (psychometric) functions and reaction-time/intensity functions obtained to the same stimuli within the same experimental paradigm for electrocutaneous stimulation.

It has also become clear recently that many factors other than intensity manipulations affect simple reaction time (e.g., Kohfeld, 1968; Grice, 1968; Murray, 1970). Among these factors, generally considered to alter the S's criteria, are contextual factors such as, for example, the range of stimuli to which the $S$ is exposed during the experiment. Murray (1970) has reported data indicating that the level as well as the slope of the reaction-time/intensity function for auditory stimuli are altered, when Ss are presented with stimuli extending over a broad intensity range (from weak to intense), relative to when they are presented with stimuli extending over a limited low-intensity range.

Since one of the objectives of this study is to investigate the reaction time to stimuli extending over the range encompassing the psychometric function (weak stimuli), it might add to the interpretation of the data if this study also included psychometric and reaction time measures obtained when the range of stimuli is broad (including high intensities) as well as when it is narrow (including only low-intensity stimuli).
Any experimental procedure designed to test threshold which utilizes single stimulus presentations is also capable of simultaneously measuring the reaction time of the $S$ to those stimuli to which he responds. Grossberg (1968) and Bruder and Kietzman (1973), for example, used this type of procedure to provide psychometric functions as well as reaction times to visual stimuli extending over the range of the psychometric function.

We have obtained frequency of response (psychometric) functions as well as reaction times to single electrocutaneous pulses whose intensities range from levels along the psychometric function to 10-12 dB above "threshold" ( $\mathrm{dB}$ re the intensity corresponding to $50 \%$ response on the psychometric function). This experiment was performed under two different conditions, one in which the intensity range was narrow, including only low-level stimuli, the second, in which the intensity range was broad, including low- as well as high-level stimuli.

\section{METHOD}

A pair of concentric platinum electrodes were constructed to fit into a plastic case that was strapped over the underside of the wrist in the vicinity of the ulnar nerve. The diameter of the inner electrode was $0.49 \mathrm{~cm}$ and was separated from the outer electrode by a radius of $0.525 \mathrm{~cm}$. The diameter of the two electrodes, including the plastic ring separating them, was $2.065 \mathrm{~cm}$.

A constant current stimulator (local design), powered by a Heathkit Model IP-17 regulated H.V. power supply operated at $200 \mathrm{~V}$, delivered square-wave pulses ranging from 100 micro $A$ to $5 \mathrm{~mA}$. Pulse duration and the timing of a sequence within a trial were controlled by locally designed timing and logic circuits. Pulse shape, duration, and current were calibrated with a Tektronix P6042 current probe in series with a Tektronix Type 454 A dual beam oscilloscope.

Reaction time was measured from the presentation of a stimulus to a lift of the right index finger from a switch by a counter-timer. Reaction time was measured to the nearest $100 \mathrm{microsec}$. All durations in the sequence, as well as the reaction time counter, were calibrated by a Monsanto Type $120 \mathrm{~A}$ electronic counter and were found to be accurate to within $0.1 \%$.

The $\mathrm{S}$ was seated in an armchair facing a warning light, with the electrode strapped to the underside of his left wrist. The reaction time key was fixed to the right armrest of the chair. The $S$ was instructed to place his right index finger on the switch as soon as the warning light appeared and to lift it as quickly as possible as soon as he felt anything. TheS, thus, indicated his decision as to the presence of a stimulus by the finger lift. If $1 \mathrm{sec}$ elapsed after a stimulus was presented without a response occurring, the trial was terminated and a "no" response (or miss) was recorded. Thus, only the latencies to "yes" responses were recorded. A trial sequence consisted of a warning light indicating trial onset followed by a pulse to the electrodes after a foreperiod which was $0.65,1.30$, or $1.95 \mathrm{sec}$. A stimulus was presented on every trial, no "blank" trials occurred. Pulse intensities were randomized by trial. Foreperiods were also randomized by trial, independently of the pulse parameters. Intertrial intervals were approximately $20 \mathrm{sec} .{ }^{1}$ Approximately 125 stimuli were presented during each 1 -h session. The $S$ was given two short rest periods, evenly spaced over the session.

All Ss were trained for several sessions prior to data collection. During the first several training sessions, the threshold range was 
Table 1

Results of Probit and Least-Squares Analyses for Psychometric Functions. Experiment I: Narrow Intensity Range

\begin{tabular}{|c|c|c|c|c|c|c|c|}
\hline Units & $\begin{array}{c}\text { Mean }(\mu) \\
\text { microA }\end{array}$ & $\begin{array}{l}\text { SD }(\sigma) \\
\text { microA }\end{array}$ & $\sigma / \mu$ & $x^{2}$ & df & $\mathrm{F}$ & $\mathrm{R}^{2}$ \\
\hline $\begin{array}{l}\text { 1. } \log \\
\text { Arithmetic }\end{array}$ & $\begin{array}{l}799 \\
809\end{array}$ & $\begin{array}{l}181 \\
179\end{array}$ & $\begin{array}{l}0.23 \\
0.22\end{array}$ & $\begin{array}{l}4.04 \\
6.76\end{array}$ & 3 & $82.5 \dagger \dagger$ & .96 \\
\hline $\begin{array}{l}\text { 2. } \log \\
\text { Arithmetic }\end{array}$ & $\begin{array}{l}297 \\
315\end{array}$ & $\begin{array}{l}150 \\
175\end{array}$ & $\begin{array}{l}0.50 \\
0.55\end{array}$ & $\begin{array}{l}13.28^{*} \\
11.29^{*}\end{array}$ & 3 & $34.74 \dagger$ & .92 \\
\hline $\begin{array}{l}\text { 3. Log } \\
\text { Arithmetic } \\
\text { (Repeat) }\end{array}$ & $\begin{array}{l}456 \\
470\end{array}$ & $\begin{array}{l}131 \\
143\end{array}$ & $\begin{array}{l}0.28 \\
0.31\end{array}$ & $\begin{array}{l}16.67^{*} \\
30.09^{*}\end{array}$ & 3 & $32.30 \dagger$ & .91 \\
\hline $\begin{array}{l}\text { 3. Log } \\
\text { Arithmetic }\end{array}$ & $\begin{array}{l}402 \\
399\end{array}$ & $\begin{array}{l}114 \\
136\end{array}$ & $\begin{array}{l}0.28 \\
0.33\end{array}$ & $\begin{array}{l}13.55^{*} \\
12.71^{*}\end{array}$ & 3 & $8.75^{* *}$ & .74 \\
\hline $\begin{array}{l}\text { 4. } \log \\
\text { Arithmetic }\end{array}$ & $\begin{array}{l}405 \\
399\end{array}$ & $\begin{array}{l}117 \\
130\end{array}$ & $\begin{array}{l}0.29 \\
0.33\end{array}$ & $\begin{array}{c}3.77 \\
11.91^{*}\end{array}$ & 3 & $86.79 \dagger \dagger$ & .96 \\
\hline $\begin{array}{l}\text { 5. } \log \\
\text { Arithmetic }\end{array}$ & $\begin{array}{l}1115 \\
1136\end{array}$ & $\begin{array}{l}301 \\
291\end{array}$ & $\begin{array}{l}0.27 \\
0.26\end{array}$ & $\begin{array}{l}6.2 \\
7.56\end{array}$ & 5 & $139.9+\dagger$ & .96 \\
\hline $\begin{array}{l}\text { 6. Log } \\
\text { Arithmetic }\end{array}$ & $\begin{array}{l}1140 \\
1161\end{array}$ & $\begin{array}{l}233 \\
247\end{array}$ & $\begin{array}{l}0.20 \\
0.21\end{array}$ & $\begin{array}{c}4.92 \\
10.51^{*}\end{array}$ & 3 & $142.96 \div \dagger$ & .98 \\
\hline
\end{tabular}

Table 2

Results of Probit and Least-Squares Analyses for Psychometric Functions. Experiment II: Broad Intensity Range

\begin{tabular}{|c|c|c|c|c|c|c|c|}
\hline Units & $\begin{array}{c}\operatorname{Mean}(\mu) \\
\text { microA }\end{array}$ & $\begin{array}{l}\mathrm{SD}(\sigma) \\
\text { microA }\end{array}$ & $\sigma / \mu$ & $x^{2}$ & df & F & $\mathrm{R}^{2}$ \\
\hline $\begin{array}{l}\text { 1. } \log \\
\text { Arithmetic }\end{array}$ & $\begin{array}{l}1624 \\
1694\end{array}$ & $\begin{array}{l}453 \\
500\end{array}$ & $\begin{array}{l}0.28 \\
0.29\end{array}$ & $\begin{array}{c}9.36 \\
58.53^{*}\end{array}$ & 7 & $535.65 \dagger \dagger$ & .98 \\
\hline $\begin{array}{l}\text { 2. } \log \\
\text { Arithmetic }\end{array}$ & $\begin{array}{l}630 \\
660\end{array}$ & $\begin{array}{l}231 \\
230\end{array}$ & $\begin{array}{l}0.36 \\
0.35\end{array}$ & $\begin{array}{l}5.66 \\
0.23\end{array}$ & 2 & $30.96 * *$ & .93 \\
\hline $\begin{array}{l}\text { 3. } \log \\
\text { Arithmetic }\end{array}$ & $\begin{array}{l}870 \\
892\end{array}$ & $\begin{array}{l}190 \\
201\end{array}$ & $\begin{array}{l}0.22 \\
0.22\end{array}$ & $\begin{array}{l}2.06 \\
8.30^{*}\end{array}$ & 2 & $394.65 \uparrow \dagger$ & .99 \\
\hline $\begin{array}{l}\text { 4. } \log \\
\text { Arithmetic }\end{array}$ & $\begin{array}{l}869 \\
887\end{array}$ & $\begin{array}{l}166 \\
181\end{array}$ & $\begin{array}{l}0.19 \\
0.20\end{array}$ & $\begin{array}{l}12.65^{*} \\
80.48^{*}\end{array}$ & 3 & $133+\dagger$ & .97 \\
\hline
\end{tabular}

determined and stimulus intensities selected. Care was taken to select stimulus intensities which would yield response frequencies of from $15 \%$ to $99 \%$ so as to permit both the construction of psychometric functions as well as sufficient data to evaluate the central tendencies of the reaction time distributions.

Experiment 1

In the first experiment, seven psychometric functions were obtained from six Ss (one $S$ was tested twice), using the method of constant stimuli in which five to seven different intensities of a 350 -microsec pulse were presented to each $S$ in random order. In this experiment, each $S$ was presented with intensities covering a narrow range. The stimuli differed from each other by $100 \mathrm{microA}$ or less, and the entire intensity range was 600 microA wide or less. Each intensity was presented 100 times.

\section{Experiment 2}

The second experiment was designed to obtain reaction time data for four of the same Ss as in Experiment 1, covering an intensity range which spanned the psychometric function and extended beyond the levels up to three to four times that of threshold (i.e., to approximately 10-12 dB SL). Ten different intensities of the $350-\mathrm{microsec}$ pulse were presented to each $\mathrm{S}$, with the stimulus range extending from 400 to $2,200 \mathrm{microA}$ for the $S$ with the lowest threshold to from 800 to 3,500 microA for the $S$ with the highest threshold. Each intensity level was presented approximately 150 times.

\section{RESULTS}

The psychophysical data were analyzed by Probit analysis (Finney, 1947) and by a least squares technique (to be described below) on an IBM 360/50 computer. The results are presented in Tables 1 and 2 . In addition, some representative data of Experiment 1 (for Ss 1, 4, and 6) are presented in Fig. 1 as percent response in normal probability coordinates as a function of pulse current in microamps on a logarithmic abscissa.

Psychometric functions for individual Ss are spread over a broad range so that thresholds in Experiment 1 range from 297 to 1,140 microA, with a median of 456 microA. In Experiment 2, thresholds range from 630 to 1,623 microA, with a median of 870 microA. The data, thus, appear to indicate that the psychometric functions in Experiment 2 are displaced into a region of higher intensity than in Experiment 1, reflected by an almost doubling of threshold. A paired sample $t$ test for correlated samples was used to test the increase in thresholds from Experiment 1 to Experiment 2 found for the four Ss tested in both experiments (Ss 1-4, Tables 1 and 2) and found to be significant $(\mathrm{t}=4.82$, df $=3, p \leqslant .01$ ). The $\sigma / \mu$ measures of slope (the ratio of the 


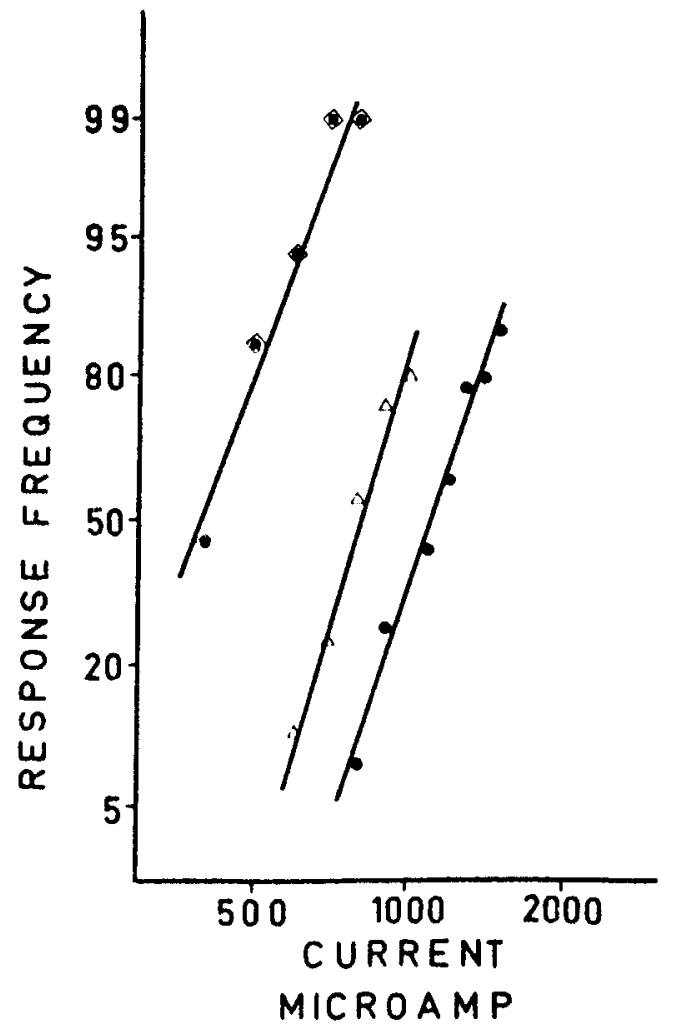

Fig. 1. Response frequency is plotted on the ordinate (on a normal probability scale) as a function of pulse current in microamps (on a logarithmic abscissa), for three Ss in Experiment 1.

standard deviation to the threshold current) for these Ss appear to decrease from Experiment 1 to Experiment 2 (compare data in Tables 1 and 2). The paired sample $t$ test, however, indicated that the differences in $\sigma / \mu$ were nonsignificant $(\mathrm{t}=1.54, \mathrm{df}=3, \mathrm{p} \leqslant .3)$.

The probit analysis (UCLA Biomedical Program BMD-03 S) yields the parameters of the best fitting line, estimates of the mean, the standard deviation of the underlying gaussian distribution, and a chi-square value to test goodness of fit of the data points to a straight line in probit coordinates. Note that for each function there are two entries in Tables 1 and 2, one for response frequency plotted as a function of stimulus intensity in arithmetic units, the other for response frequency plotted as a function of stimulus intensity in logarithmic units.

The results of this analysis seem to indicate that when response frequency is plotted as a function of stimulus current in logarithmic units, 7 out of 11 of the functions can be fitted by the cumulative gaussian distribution, as indicated by nonsignificant chi-square values. When the independent variable is expressed in arithmetic units, however, 8 of the 11 functions seem to deviate significantly from the cumulative gaussian distribution. Since for several functions, the points do not disperse evenly, one may not attach great significance to the fact that some functions differ on the chi-square test from the cumulative normal function. Even so, however, the data seem to indicate that a logarithmic transform of the intensity variable is indicated for producing functions best fitted by cumulative normal distributions.

A further test of the hypothesis that these data can be described by the cumulative gaussian distribution was performed by testing the probit data directly for linearity by a least squares technique (since probit coordinates correspond to a cumulative gaussian density function in linear coordinates). This program (Smillie, 1969) tests significance of linearity in the data by an $F$ test as well as yielding the regression coefficient. The results of this test are also shown in Tables 1 and 2, and confirm the significance of linearity for all functions as well as accounting for $90 \%$ to $99 \%$ of the variance for 10 of the 11 functions and $74 \%$ for 1 function when the data are expressed by probit coordinates. These analyses support the argument that the psychophysical data represent an underlying gaussian distribution when the independent variable is expressed in logarithmic units. A further indication of this is seen in Fig. 1, in which 3 functions of three different $\mathrm{Ss}$ in Experiment 1 are drawn and clearly fitted by straight lines, although the 3 functions differ in placement along the abscissa (mean) and appear to differ slightly in slope (variance).

The reaction time (RT) data were analyzed initially in terms of RT probability distributions for each stimulus intensity for each $\mathrm{S}$. The distributions were generally skewed, so that the median, rather than the mean, was taken as the central tendency measure. Only RTs for distributions having an $\mathbf{N}$ of $\mathbf{3 0}$ or more were analyzed. No stimulus intensity was detected on $100 \%$ of the trials in Experiment 1, in contrast to Experiment 2, in which most stimulus intensities were detected on $100 \%$ of the trials.

The median reaction times for Experiment 1 are plotted in Fig. 2 on the ordinate in milliseconds as a function of stimulus current in microamps on a logarithmic abscissa. Data for each $S$ are plotted separately. The Ns upon which the medians are based increase as the stimulus current increases, since percent detection also increases as a function of stimulus current. All of the data plotted in Fig. 2 represent RTs to stimuli detected on $99 \%$ or less of the trials. Reaction time for all Ss shows an overall decrease as stimulus current increases, although there are some reversals in the data. Individual differences appear mostly as displacement of the data on the ordinate and abscissa axes.

The median reaction time data for Experiment 2 are plotted in Fig. 3 (open circles) on the ordinate in milliseconds as a function of stimulus current in microamps on a logarithmic abscissa. Data for each $\mathrm{S}$ are plotted separately. Furthermore, the data for each $\mathrm{S}$ from Experiment 1 (Fig. 2) are also replotted in Fig. 3 (closed circles). The response frequencies for those stimuli detected on less than $100 \%$ of the trials are noted in this figure.

Note that for all Ss, the RT functions for 
Fig. 2. Median reaction time in milliseconds is plotted on the ordinate as a function of current in microamps on a logarithmic abscissa. Data are plotted for six Ss in Experiment 1.

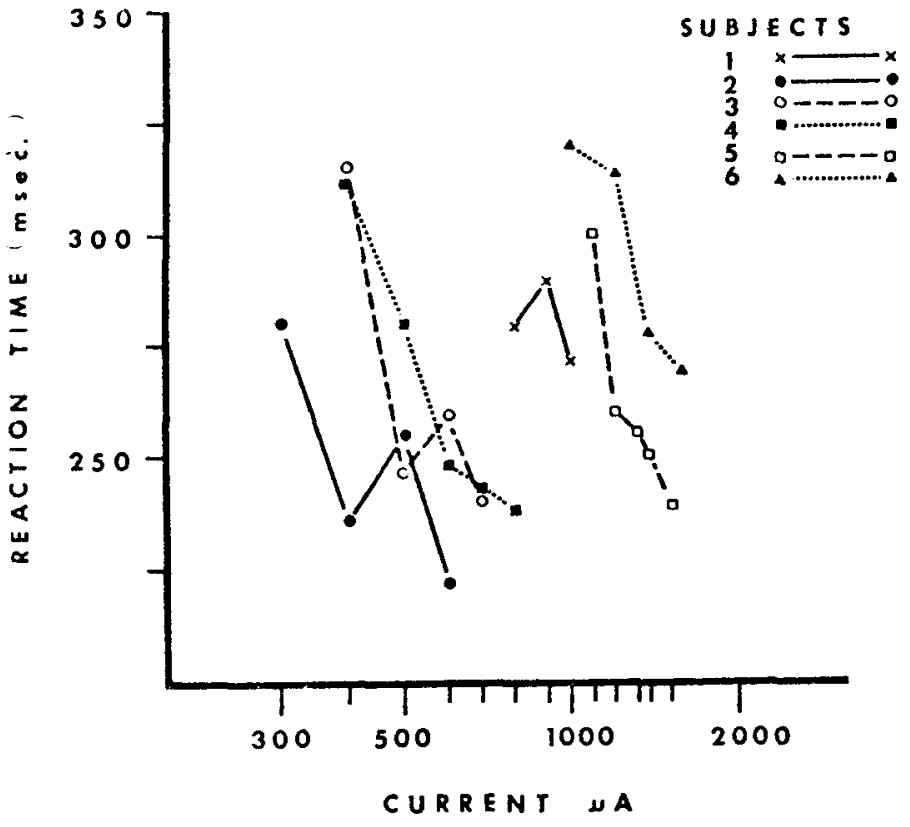

Experiment 1 are to the left of, and below, the RT functions generated in Experiment 2. That is, the RT functions for Experiment 2 are displaced into a more intense stimulus region and relatively longer RTs than the functions for Experiment 1.

In general, the RTs generated in Experiment 2 to stimuli extending over a range approximately three times more intense than threshold yield monotonic and negatively decelerating functions. The RT functions for Ss 1,2 , and 3 do not appear to approach asymptote. The RT function for S 4, however, does appear to approach an asymptote. All of the data (Experiment 2) for a given

$\mathrm{S}$, regardless of the response frequency (equal to or less than $100 \%$ ), appear to fall on the same function.

\section{DISCUSSION}

The major finding in this study concerns the generation of psychometric and reaction time functions to electrocutaneous stimuli spanning the psychometric function and beyond. The data indicate the effect of manipulating stimulus intensity, as well as the effect of the context within which the stimuli are presented.

Although all of the psychometric functions generated

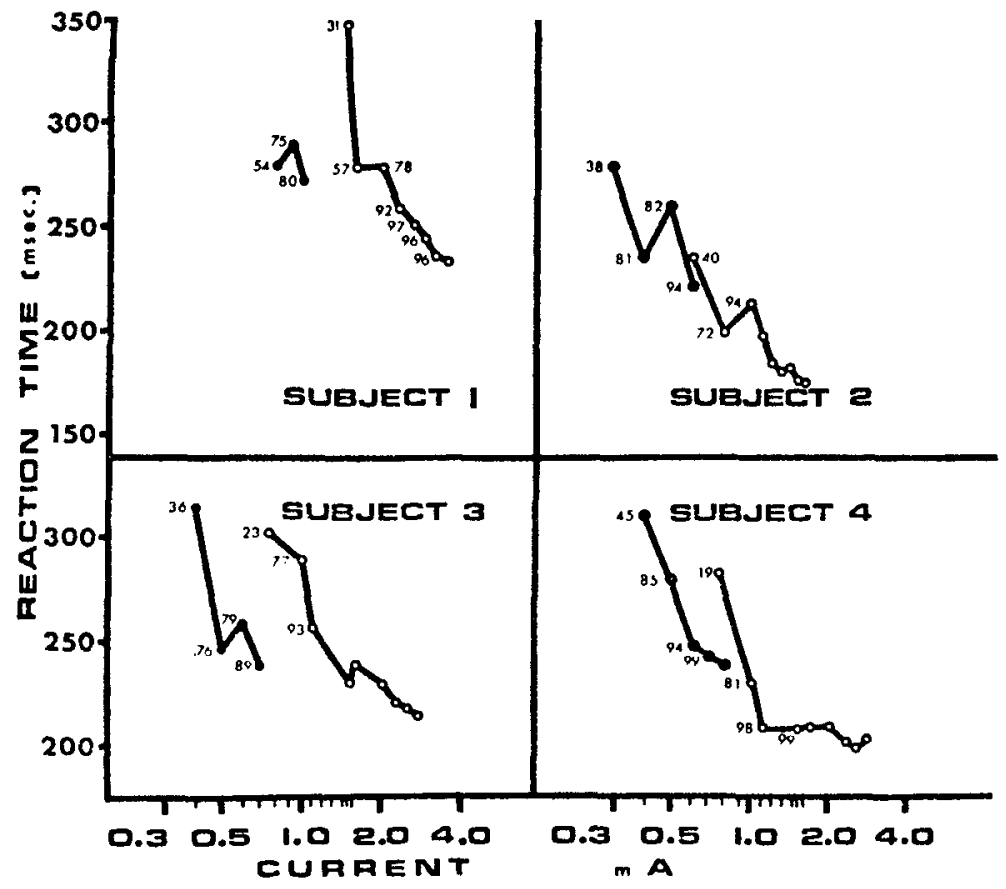

Fig. 3. Median reaction time in milliseconds is plotted on the ordinate as a function of current in milliamps on a logarithmic abscissa, separately for each of the four Ss in Experiment $2(\mathrm{o})$. The RT data of Experiment 1 is also plotted for each $S(\bullet)$. In addition, the response frequencies are noted for those intensities detected on less than $100 \%$ of the trials. 
in this study could be fitted by cumulative normal distributions when response probability was plotted as a function of $\log$ stimulus current, the slopes of the functions in this study are much shallower than those reported by Rollman (1969a), thus indicating more variance. Rollman reported a median ratio of the standard deviation to threshold $(\sigma / \mu)$ of 0.08 , which is much lower than the typical visual psychometric functions, such as 0.30 (Heinz \& Lippay, 1928, cited by Rollman, 1969a), 0.311 to 0.539 (Blackwell, 1963), 0.42 (Hecht, Shlaer, \& Pirenne, 1942), and 0.58 (Bouman \& Van der Velden, 1947). The median $\sigma / \mu$ ratio in Experiment 1 of this study was 0.28 (median of seven functions), and in Experiment 2 it was 0.25 (median of four Ss) lower than reported for the studies in vision, but nevertheless about three times as large as the value reported by Rollman. We hypothesize that this difference is due to the type of task the Ss were required to perform, namely, a combination reaction-time/detection task. The additional requirement to respond as quickly as possible to a stimulus in the vicinity of threshold may tend to increase variance, which is reflected as a decrease in slope. Bruder and Kietzman (1973) recently utilized a threshold visual study to measure reaction time to stimulus intensities ranging over the psychometric function. A probit analysis of their psychometric data yields a $\sigma / \mu$ ratio of 0.46 , which is among the higher estimates of $\sigma / \mu$ ratios for visual data. This tends to confirm our contention that a method combining RT and a psychometric task adds variance and tends to decrease the slope of the psychometric function for all modalities.

The data of those Ss showing no reversal in their RT vs stimulus intensity functions were averaged separately for Experiment 1 and for Experiment 2, to give us some indication of the overall relationship between response frequency and reaction time to the same stimulus intensities. In Experiment 1, there is an average decrease in reaction time of $64 \mathrm{msec}$ for an average increase in stimulus intensity of $0.22 \mathrm{log}$ units. This corresponds to an average increase in probability of from $39 \%$ to $90 \%$ detection. In Experiment 2, there was an average decrease in reaction time of $78 \mathrm{msec}$ over an average increase in stimulus intensity of $0.26 \mathrm{log}$ units. This corresponds to an average increase in probability of from $28 \%$ to $93 \%$.

An analysis of the data presented by Bruder and Kietzman (1973) for luminance manipulations indicates a very similar decrease in RT occurring over the stimulus range spanning the psychometric function. Of the two Ss whose data are shown in the Bruder and Kietzman study of visual reaction times to stimuli spanning the psychometric function, one yields a decrease of $67 \mathrm{msec}$ over a stimulus range of $0.35 \log$ units, corresponding to an increase in detection of from $30 \%$ to $92 \%$. The other $S$ shows a decrease of $76 \mathrm{msec}$ over a stimulus range of $0.39 \log$ units, which corresponds to an increase in detection of from $39 \%$ to $98 \%$. On another segment of the function, this $S$ yields a decrease of $67 \mathrm{msec}$ for an intensity increase of $0.38 \mathrm{log}$ units, corresponding to an increase in detection of from $22 \%$ to $88 \%$.

Since the steepest segment of the RT-stimulus intensity function is to be found over the stimulus range corresponding to lower probabilities of stimulus detection, these data indicate that the changes in reaction time reported for this study both in Experiment 1 and Experiment 2 are quite comparable to those found in a similar study of visual RT. The range of change in frequency of response associated with these RT changes is also quite comparable. In the Bruder and Kietzman study (1973), however, the luminance had to be increased by a larger factor to obtain these changes in response frequency and $\mathrm{RT}$, as indicated by their $\sigma / \mu$ ratio of 0.46 compared to the change in stimulus intensity required for a comparable decrease in RT and increase in frequency of response reported in this study (which yielded an estimate of 0.28 for the $\sigma / \mu$ ratio for the first experiment and 0.25 for the second experiment). It appears, therefore, that decreases in reaction time as a function of increases in the intensity of electrocutaneous stimuli show the same sensitivity to small changes in intensity over the psychometric stimulus range which is seen for the psychophysical functions.

The data for Experiment 2 include RTs to stimulus intensities detected on $100 \%$ of the trials as well as to those detected on less than $100 \%$ of the trials. All of the data for a given $S$, however, regardless of the frequency of detection, appear to fall along the same function, implying the same RT mechanism operating for all stimuli regardless of the response frequency. These stimulus intensities were randomized by trial, and these conclusions, therefore, are limited to such a technique. No inference may be drawn with respect to what the finding might be were the different stimulus intensities to be fixed within a block of trials and varied across blocks.

Altering the context within which the stimuli are presented, by increasing the number of stimuli and the intensity range to which they are exposed, serves to alter both the estimate of threshold and the placement of the reaction time functions along the intensity axis. The question arises as to what framework is suited to data of this nature. We believe that these data may be understood with reference to the decision-theory type of model used to interpret reaction time data.

One of the earlier applications of the decision-theory approach to reaction time (RT) data was made by McGill $(1961,1963)$, who presented a model designed to relate decreases in simple reaction time to increases in stimulus intensity. McGill observed that RT distributions, plotted with stimulus intensity as parameter, show fixed delays, i.e., as stimulus intensity increases, the distributions move in a parallel fashion into shorter RT regions, and concluded from this that in a RT task the $S$ makes decisions based upon a parameter 
determined by stimulus intensity. According to this model, a sensory input is regarded as giving rise to a series of impulses which accumulate at some point in the nervous system; the impulse rate increases with stimulus intensity. When the cumulative count reaches some determined number, the S's decision criterion, he will respond. Trial-to-trial variability is associated with a sensory input rate which fluctuates from input to input. Mean RT reflects the amount of time it takes for the mean impulse rate to reach criterion (number of accumulated impulses). McGill's model is based upon the assumption that the RT criterion remains constant for large blocks of trials and that the major source of variance lies in the sensory input (impulse rate fluctuations). The RT decision criterion, i.e., the number of accumulated impulses needed to respond, however, in McGill's view, is the parameter most likely to be manipulated by training, instructions, contextual cues, and the general overall experimental design.

Grice (1968) has adopted the decision-theory model for RT data, but has altered the emphasis as to the source of variability. Grice argues that it is not reasonable to assume that the RT criterion remains constant over a large block of trials. Rather, it is more reasonable to assume that the RT criterion is subject to moment-to-moment fluctuations, being strongly influenced by a variety of experimental and individual-difference variables, whereas the sensory input may be considered as a relatively stable process, determined by stimulus energy. Criterion fluctuations are thus regarded, by Grice, as being the major source of trial-to-trial variability rather than fluctuations in sensory input rate.

According to Grice' fluctuating-criterion theory of $\mathrm{RT}$, the criterion is also determined by the range of stimuli to which the $S$ is exposed. Data presented by Grice and Hunter (1964) indicate that if Ss receive only low-intensity stimuli they will adopt a lower criterion and have relatively shorter reaction times than if they receive only intense stimuli. Kohfeld (1968) reported that Ss preexposed to high-intensity tones have longer RTs to tones extending over a broad intensity range than do Ss preexposed to low-intensity tones, and that this effect continues over to sessions in which reaction time was measured without preexposure. Grice (1968) explains Kohfeld's data in terms of varying criteria based on the assumption that the S's detection criterion is determined in part by the intensity of the preadapting stimuli. Furthermore, Ss receiving stimuli extending over a broad range, from weak to intense, can be expected to have relatively longer RTs than Ss receiving stimuli extending over a limited low-intensity range. Murray's findings (1970) seem to confirm this prediction. One might, accordingly, expect longer reaction times to the same stimuli merely by altering the context, i.e., by broadening the range of stimuli within which these stimuli are presented. One of the results of the present study, which indicates that the functions of the same Ss are displaced into longer RT ranges as the range of stimuli to which the Ss are exposed is expanded to include high intensities (compare the RT results in Experiment 1 with the results in Experiment 2), is thus predicted by Grice's model.

The overall results indicate that RT changes to electrocutaneous stimuli whose intensities span the psychometric function are similar to those found in other modalities. The stimulus range is smaller, however, thus indicating greater sensitivity in terms of a large decrease in RT as a function of a small increase in intensity. These findings thus indicate that measures of RT are consistent with the psychophysical findings on electrocutaneous stimulation reported in the literature (Hahn, 1958; Green, 1962; Rollman, 1969a).

\section{REFERENCES}

Blackwell, H. R. Neural theories of simple discrimination Journal of the Optical Society of America, 1963, 53, 129-160. Bouman, M. A., \& Van der Velden, H. A. The two-quanta explanation of the dependence of the threshold value and visual acuity on the visual angle and the time of observation. Journal of the Optical Society of America, 1947, 37, 908-919.

Bruder, G. E., \& Kietzman, M. L. Visual temporal integration for threshold, signal detectability, and reaction time measures. Perception \& Psychophysics, 1973, 13, 293-300.

Carterette, E, C. Friedman, M. P. \& Cosmides, R. Reaction time distributions in the detection of weak signals in noise. Journal of the Acoustical Society of America, 1965, 38, 531-542.

Emmerich, D. S., Gray, J. L., Watson, C. S., \& Tanis, D. C. Response latency, confidence, and ROCs in auditory signal detection. Perception \& Psychophysics, 1972, 11, 65-72.

Finney, D. J. Probit analysis. Cambridge: Cambridge University Press, 1947.

Gescheider, G. A., Wright, J. H., Weber, B. J., Kirchner, B. M., \& Milligan, E. A. Reaction time as a function of the intensity and probability of occurrence of vibrotactile signals. Perception \& Psychophysics, 1969, 5, 18-20.

Green, R. T. The absolute threshold of electric shock. British Journal of Psychology, 1962, 53,107-115.

Grice, G. R. Stimulus intensity and response evocation. Psychological R eview, 1968, 75, 359-373.

Grice, G. R., \& Hunter, J. J. Stimulus intensity effects depend upon the type of experimental design. Psychological Review, $1964,71,247-256$.

Grossberg, M. The latency of response in relation to Bloch's law at threshold. Perception \& Psychophysics, 1968, 4, 229-232.

Grossberg, M. "Backward masking" of simple detection latencies. Perception \& Psychophysics, 1970, 8, 308-312.

Hahn, J. F. Cutaneous vibratory thresholds for square-wave electrical pulses. Science, 1958, 127, 879-880.

Hecht, S. Shlaer, S., \& Pirenne, M. Energy, quanta, and vision. Journal of General Physiology, 1942, 25, 819-840.

Heinz, M., \& Lippay, F. Über die Beziehungen Zwischen der Unterschiedsempfindlichkeit und der Zahl der erregten Sinneselem ente: 1. Pflügers Archiv für die gesamte Physiologie d. Menschen u. d. Tiere, 1928, 218, 437-447.

Kietzman, M. L. \& Gillam, B. J. Visual temporal integration and simple reaction time. Perception \& Psychophysics, 1972, 11, 333-340

Kohfeld, D. L. Stimulus intensity and adaptation level as determinants of simple reaction time. Journal of Experimental Psychology, 1968, 76, 468-473.

Luce, R. D., \& Green, D. M. A neural timing theory for response times and the psychophysics of intensity. Psychological Review, $1972,79,14-57$.

McGill, W. J. Loudness and reaction time. Acta Psychologica, $1961,19,193-199$.

McGill, W. J. Statistic latency mechanisms. In R. D. Luce, R. R. Bush, and E. Galanter (Eds.), Handbook of mathematical psychology. Vol. 1. New York: Wiley, 1963.

Murray, H. G. Stimulus intensity and reaction time: Evaluation of a decision-theory model. Journal of Experimental Psychology, 1970, 84, 383-391.

Raab, D. H. Effect of stimulus-duration on auditory reaction time. American Journal of Psychology, 1962, 75, 298-301.

Raab, D. H., \& Fehrer, E. The effect of stimulus duration and luminance on visual reaction time. Journal of Experimental Psychology, 1962, 64, 326-327. 
Rollman, G. B. Electrocutaneous stimulation: Psychometric functions and temporal integration. Perception \& Psychophysics, 1969a, 5, 289-293.

Rollman, G. B. Detection models: Experimental tests with electrocutaneous stimuli. Perception \& Psychophysics, 1969b, 5, 377-380.

Rosner, B. S. Temporal interaction between electrocutaneous stimuli. Joumal of Experimental Psychology, 1964, 67, 191-192.

Sherrick, C. E. Jr. Effects of double simultaneous stimulation of the skin. American Journal of Psychology, 1964, 77, 42-53.

Smillie, K. W. Statpack 2: An APL statistical package. (2nd ed.) Edmonton: University of Alberta, February 1969.

Sticht, T. G., \& Foulke, E. Reaction time to electrocutaneous onset and offset stimulation. Psychonomic Science, 1966a, 4, 213-214.

Sticht, T. G., \& Foulke, E. Reaction time to the onset and offset of electrocutaneous stimuli as a function of rise and decay time. Perception \& Psychophysics, 1966b, 1, 361-365.

Teichner, W. H. \& Krebs, M. J. Laws of the simple visual reaction time. Psychological Bulletin, 1972, 75, 344-358.
Vaughan, H. G., Jr., Costa, L. D., \& Gilden, L. The functional relation of visual evoked response and reaction time to stimulus intensity. Vision Research, 1966, 6, 645-656.

\section{NOTE}

1. Data on the masking of electrocutaneous stimuli applied to the same skin locus indicated that even for intensities very much higher than the highest intensity used in the studies reported in this paper no residual effect (measured by threshold shift) can be found at interstimulus intervals longer than $1 / 2$ sec (Rosner, 1964; Sherrick, 1964). An intertrial interval of 20 sec thus seems quite sufficient to eliminate residual stimulus effects.

(Received for publication June 11, 1973; revision received August 17, 1973.) 